\title{
Cytokeratin 20 negative Merkel cell carcinoma consistent with negative Merkel cell polyomavirus
}

\author{
Osung Kwon, Hyun Chung, Joonsoo Park \\ Department of Dermatology, Catholic University of Daegu School of Medicine, Daegu, Korea
}

\begin{abstract}
Merkel cell carcinoma (MCC) is a rare neuroendocrine tumor that is highly aggressive in nature and indolent in progression. The common risk factors for MCC are senility, prolonged exposure to sunlight, and immune deficient states. Moreover, Merkel cell polyomavirus has recently been characterized to be significantly associated with pathogenesis of MCC, including the expression of Cytokeratin 20 (CK20). Diagnosis is often difficult since histopathological results require a number of differential diagnoses through immunohistochemical (IHC) stains with other cutaneous malignancies. A 67-year-old man presented with a solitary domeshaped erythematous round mass on the left upper arm for 2 months. Biopsy and IHC studies revealed findings consistent with Merkel Cell Carcinoma of neuroendocrine origin. Common IHC stains usually confirm positive findings for CK20, which is also recognized as the key component in making the diagnosis. We present a CK20 negative MCC in light of expanding the knowledge of unusually stained IHC results in MCC.
\end{abstract}

Keywords: Cytokeratin 20; Merkel cell carcinoma; Merkel cell polyomavirus

\section{INTRODUCTION}

Merkel cell carcinoma (MCC) is a rare neuroendocrine tumor that is highly aggressive in nature and indolent in progression [1-2]. The common risk factors for MCC are senility, prolonged exposure to sunlight, and immune deficient states. Moreover, Merkel cell polyomavirus (MCPyV) was recently shown to be significantly associated with the pathogenesis of MCC, including the expression of Cytokeratin 20 (CK20) [3]. The diagnosis is often difficult because histopathological results require a number of differential diagnoses through immunohistochemical (IHC) stains with other cutaneous malig-

Received: May 26, 2017, Revised: June 26, 2017

Accepted: July 4, 2017

Corresponding Author: Joonsoo Park, Department of Dermatology, Catholic University of Daegu School of Medicine, 33 Duryugongwon-ro 17-gil, Nam-gu, Daegu 42472, Korea

Tel: +82-53-650-4161, Fax: +82-53-650-4891

E-mail: g9563009@cu.ac.kr nancies. We present a CK20 negative MCC consistent with negative $\mathrm{MCPyV}$ in light of expanding the knowledge regarding aberrant IHC results in MCC.

\section{CASE}

A 67-year-old man was admitted to the hospital with a $2.2 \times 2.0 \mathrm{~cm}$ dome-shaped erythematous mass on his left upper arm. The lesion had started as an erythematous papule the size of a millet grain 2 months prior to admission, and had gradually grown thereafter. The patient was being treated for diabetes and hypertension, but had no specific family history. Physical examinations showed no findings of interest other than the skin lesion, and the complete blood count and peripheral blood smear were also unremarkable. Examination of the skin showed a relatively firm, even, raised, dome-shaped, and bright red lump on the upper left arm with a fairly clear margin (Fig. 1A). The lesion did not show any additional symptoms, such as heat, tenderness, or exudation.

Copyright $(\odot 2017$ Yeungnam University College of Medicine

This is an Open Access article distributed under the terms of the Creative Commons Attribution Non-Commercial License (http://creativecommons.org/licenses/by-nc/4.0/) which permits unrestricted non-commercial use, distribution, and reproduction in any medium, provided the original work is properly cited. 
Biopsy of the center of the lesion showed epidermal atrophy and infiltration of the dermis by various cells, including clusters of tumor cells surrounded by lymphocytes and other inflammatory cells (Fig. 1B, 1C). The tumor cells had vesicular nuclei and scanty cytoplasm, and some tumor cells showed coarse or clumped chromatin scattered throughoutthe cell (Fig. 1D). Based on the above clinical and histological findings, malignant lymphoma, metastatic small cell carcinoma, MCC, and malignant melanoma were all suspected. Upon IHC tests performed for a differential diagnosis, pan-CK, CD56, chromogranin, and Ki-67 (40\%) were positive, and leukocyte common antigen (LCA), CK20, CK7, and thyroid transcription factor-1 (TTF-1) were negative (Fig. 2).

Based on all of these findings, the patient was diagnosed with MCC. Because no distant metastasis was observed upon subsequent positron emission tomography-computed tomography, the final diagnosis was primary MCC of the skin (Fig.
3A). Further testing of MCPyV was conducted to evaluate the cause of the IHC stain results and was consistently negative. The patient underwent extensive excision of the lesion with a $1.5 \mathrm{~cm}$ margin and skin flap surgery (Fig. 3B). A sentinel lymph node biopsy did not show any findings of lymph node metastasis. After completing radiotherapy, the patient is currently in follow-up with no findings of metastasis or relapse.

\section{DISCUSSION}

MCC is a rare neuroendocrine tumor that undergoes malignant progression [1-2]. Since it was first published by Tang and Toker in 1978, there have been constant reports on MCC. Risk factors include old age, ultraviolet light exposure, immune impairment, and a strong association with MCPyV [1,4].

Clinically, MCC presents as an asymptomatic, non-specific,
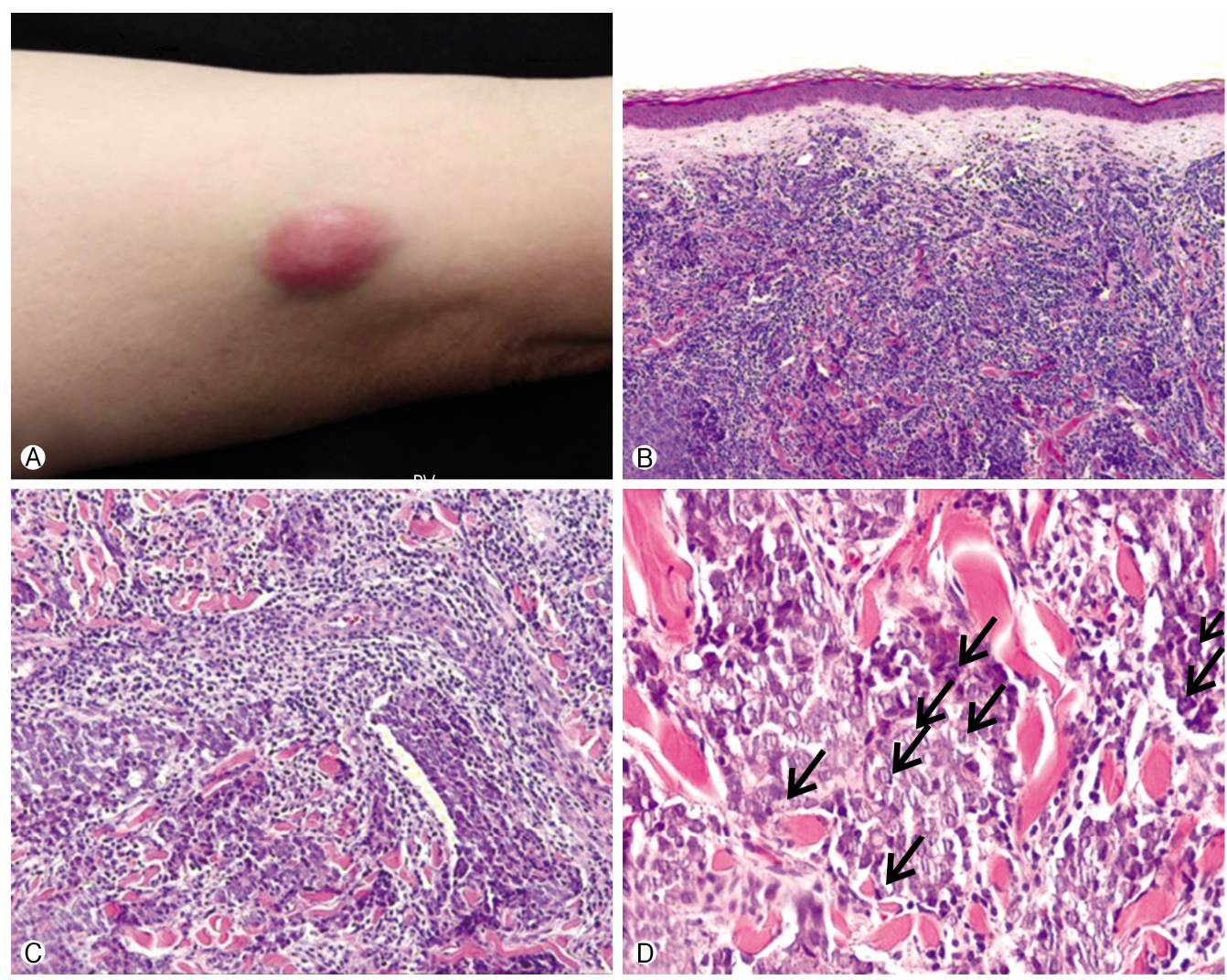

Fig. 1. (A) Clinical image of the patient presenting with a solitary $2.2 \times 2.0 \mathrm{~cm}$ sized dome-shaped erytheatmous elevated mass on left upper arm. (B) Scanning view reveals epidermal atrophy and infiltration of the dermis by various cells with noticeable grenz zone (H\&E stain, $\times 40)$. (C) Various cells including clusters of tumor cells surrounded by lymphocytes and other inflammatory cells (H\&E stain, $\times 100)$. (D) Tumor cells had vesicular nuclei and scanty cytoplasm, and some tumor cells showed coarse or clumped chromatin scattered throughout the cell (black arrows) (H\&E stain, $\times 400)$. 
erythematous papule or nodule, and it has been reported to be accompanied by ulcers on rare occasions. Histological exa- mination shows clusters of tumor cells from the dermis to the subcutaneous fat layer, but they rarely infiltrate the epi-
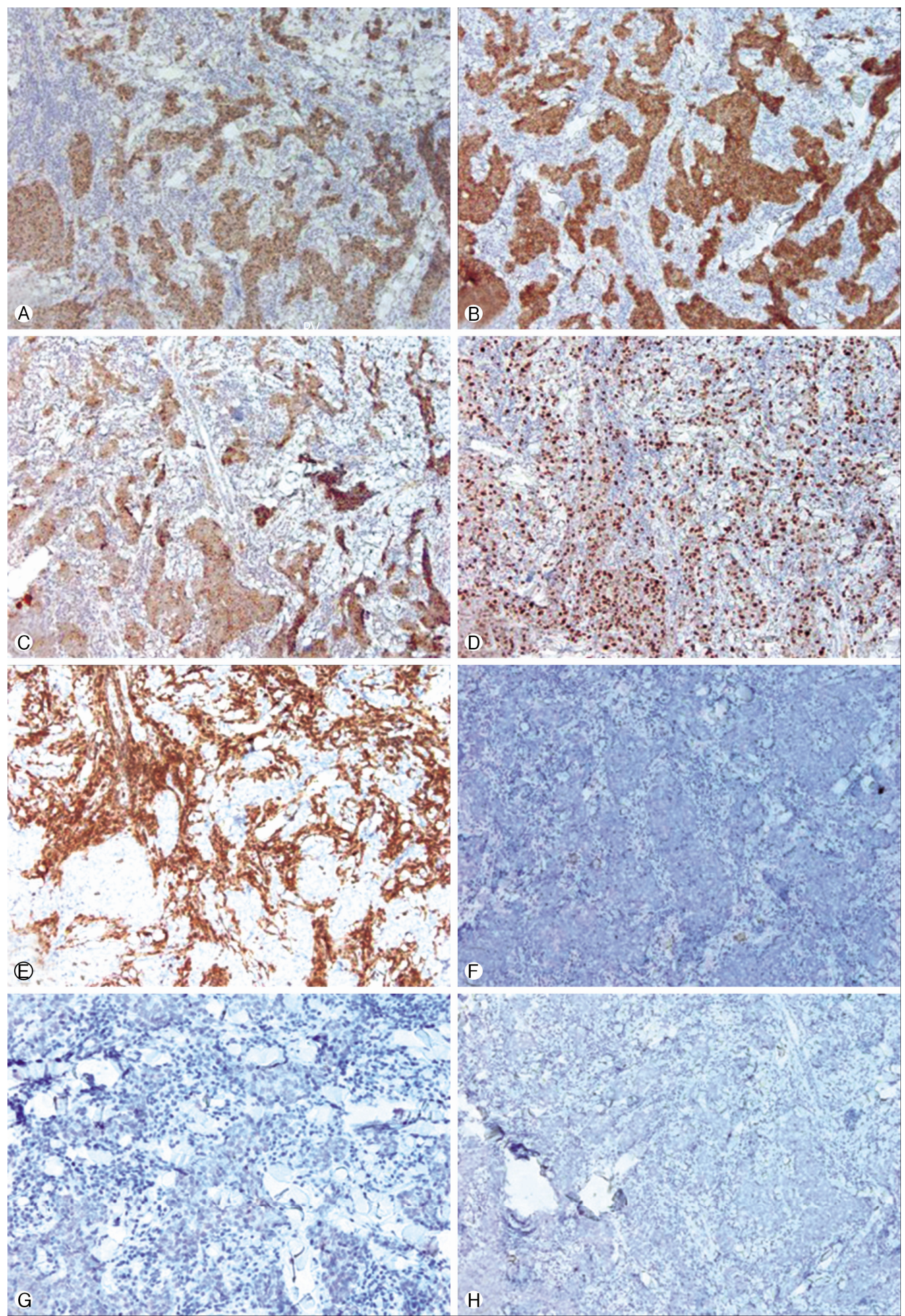

Fig. 2. Tumor cells express positive immunoreactivity for (A) pancytokeratin $(\times 100)$, (B) CD56 $(\times 100)$, (C) chromogranin $(\times 100)$, (D) Ki-67 $(\times 100)$, negative immunoreactivity for $(\mathrm{E})$ leukocyte common antigen (×100), (F) CK20 $(\times 100),(\mathrm{G})$ CK7 $(\times 100)$, and $(\mathrm{H})$ thyroid transcription factor-1 $(\times 100), \mathrm{CK}$, cytokeratin. 

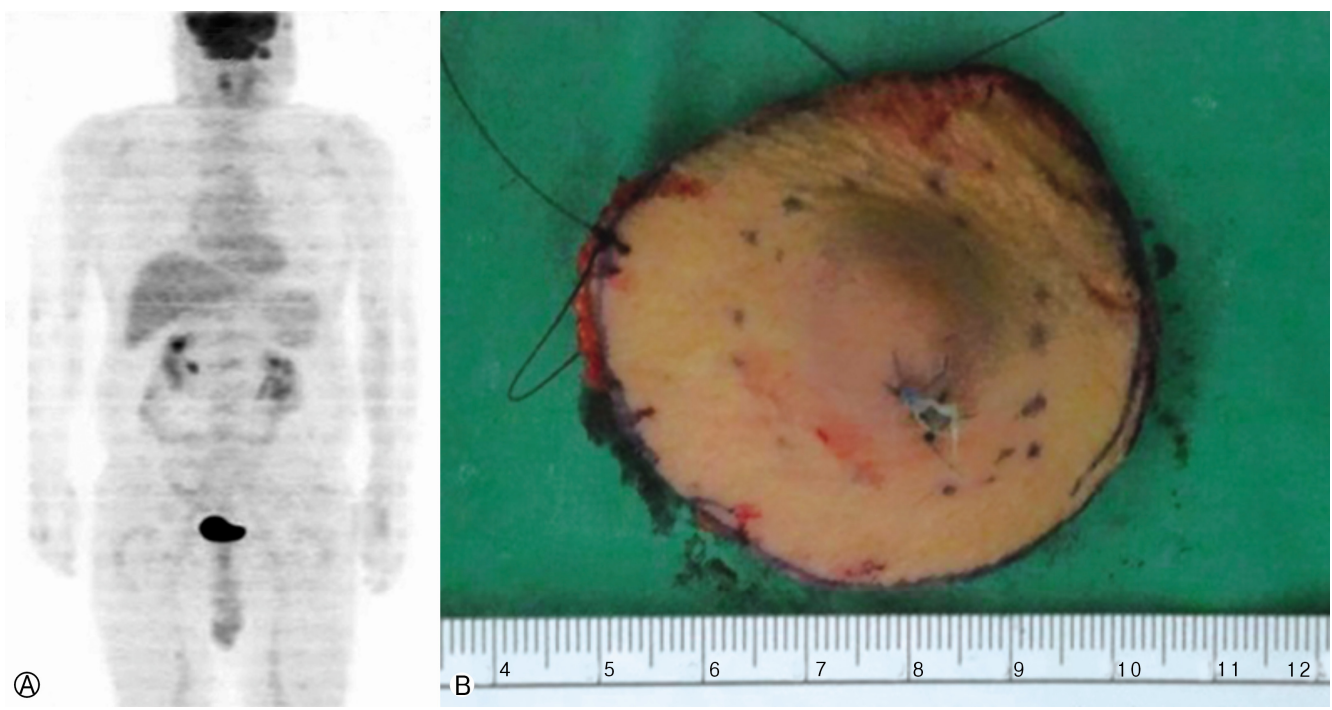

Fig. 3. (A) Positron emission tomography-computed tomography reveals no distant metastasis. (B) Gross image of the specimen after extensive excision of the lesion with a $1.5 \mathrm{~cm}$ margin.

dermis. Individual cells have a characteristic 'salt-and-pepper' appearance, because of round, granular nucleus and the lack of cytoplasm [5].

The tumor cells are positive for epithelial markers, as well as for the neuroendocrine markers chromogranin and synaptophysin, and the neural marker CD56 [6-7]. The majority of Merkel cells are positive for CK20. During histological examinations, additional stains are required to differentiate MCC from diseases with a similar appearance. The present case could be differentiated from lymphoma and malignant melanoma based on negative tests for LCA, S-100, Melan-A, and $\mathrm{HMB} 45$, while positive tests for the neuroendocrine and neural markers chromogranin, synaptophysin, and CD56 revealed that the tumor was of neuroendocrine origin. A negative result in an additional test for TTF-1 ruled out small cell carcinoma, but the negative result for CK20 was different from the typical findings for a MCC [6-8].

Approximately 5-25\% of all MCCs are negative for CK20, but the cause of this is not yet clear [1,5]. Miner et al. reported that CK20-negative patients were less frequently associated with $\mathrm{MCPyV}$, which is known to be a major risk factor for MCC [9]. Harms et al. reported that 80\% of CK20-positive MCC patients were associated with MCPyV oncogenes. Next-generation sequencing techniques were used to show the presence of virus-independent mechanisms such as BAP1, or TP53 and RB1 inactivation in CK20-negative MCC patients, and were able to interpret these as findings of CK20 negativity in MCC to date [10].

Prior to this study, there have been 12 case reports and manuscripts on MCC were published in the Korean Journal of Dermatology, but only three of these were CK20-negative cases. The present case reveals IHC signs that may present differently in a rare form of MCC; thus, we present this case together with a review of the literature.

\section{ACKNOWLEDGEMENT}

The authors declare acknowledgement to any corporate body regarding the article.

\section{CONFLICT OF INTEREST}

No potential conflict of interest relevant to this article was reported.

\section{ORCID}

Osung Kwon, https://orcid.org/0000-0001-8527-5270

Joonsoo Park, https://orcid.org/0000-0003-1354-2311

\section{REFERENCES}

1. Pulitzer M. Merkel cell carcinoma. Surg Pathol Clin 2017;10: 399-408. 
2. Rehailia-Blanchard A, Pigné G, Guy JB, Vallard A, El Meddeb Hamrouni A, Rancoule C, et al. Care of merkel cell carcinoma and role of the radiotherapy. Bull Cancer 2017;104:101-8.

3. Iwasaki T, Matsushita M, Nonaka D, Murakami I, Hayashi K. Comment on 'Cytokeratin 20-negative Merkel cell carcinoma is infrequently associated with the Merkel cell polyomavirus'. Mod Pathol 2016;29:89-90.

4. Tang CK, Toker C, Nedwich A, Zaman AN. Unusual cutaneous carcinoma with features of small cell (oat cell-like) and squamous cell carcinomas. A variant of malignant Merkel cell neoplasm. Am J Dermatopathol 1982;4:537-48.

5. Campillo R, Gil-Carcedo E, Alonso D, Vallejo LA, Oñate JM, Gil-Carcedo LM. Primary cutaneous neuroendocrine carcinoma, Merkel cell carcinoma. Case series 1991-2012. Acta Otorrinolaringol Esp 2013;64:396-402.

6. Llombart B, Requena C, Cruz J. Update on Merkel cell carcinoma: epidemiology, etiopathogenesis, clinical features, diagnosis, and staging. Actas Dermosifiliogr 2017;108:108-19.
7. Jensen K, Kohler S, Rouse RV. Cytokeratin staining in Merkel cell carcinoma: an immunohistochemical study of cytokeratins 5/6, 7, 17, and 20. Appl Immunohistochem Mol Morphol 2000;8:310-5.

8. Ahmadi Moghaddam P, Cornejo KM, Hutchinson L, Tomaszewicz K, Dresser K, Deng A, et al. Complete spontaneous regression of Merkel cell carcinoma after biopsy: a case report and review of the literature. Am J Dermatopathol 2016; 38:e154-8.

9. Miner AG, Patel RM, Wilson DA, Procop GW, Minca EC, Fullen DR, et al. Cytokeratin 20-negative Merkel cell carcino$\mathrm{ma}$ is infrequently associated with the Merkel cell polyomavirus. Mod Pathol 2015;28:498-504.

10. Harms PW, Collie AM, Hovelson DH, Cani AK, Verhaegen ME, Patel RM, et al. Next generation sequencing of Cytokeratin 20-negative Merkel cell carcinoma reveals ultravioletsignature mutations and recurrent TP53 and RB1 inactivation. Mod Pathol 2016;29:240-8. 